\title{
Pedagogical conditions for the formation of foreign-language sociocultural competence of cadets of educational organizations of the Federal Penal Service of Russia
}

\author{
Nina Shilina*, Galina Aksenova, Irina Ganishina, and Polina Aksenova \\ Academy of Law and Management of the FPS of Russia, Ryazan, Russian Federation
}

\begin{abstract}
Currently it is necessary to learn cultures of other people, and it is therefore important to find new areas and forms of cultural cooperation. One way to meet these challenges is to learn foreign languages. The sociocultural component in the content of foreign language instruction plays a significant role in the development of the cadets personality, as it provides an opportunity not only to familiarize themselves with the heritage of the country's culture of its target language country, but also to compare it with the cultural values of his country, which contributes to the formation of the common culture of a cadet. The relevance of problem of the formation of foreign-language sociocultural competence of cadets of the educational organizations of the Federal Penal Service (FPS) of Russia is defined by the social order of society which found the reflection in the Concept of Development of the Penal system of the Russian Federation till 2020 and also it is defined by the increased requirements of acquisition of a foreign language and search of the ways of the formation of foreignlanguage sociocultural competence promoting formation of bases intellectual, the cultural, professional and communicative developed identity of a specialist.
\end{abstract}

Among the reasons for improving the foreign-language sociocultural competence of cadets of educational organizations of the Federal Penal Service of the Russian Federation are the following:

1) requirements of the State standards, according to which graduates must master the ability to communicate in business, professional communication in one of the foreign languages, as the development of international cooperation, study and dissemination of foreign experience in the field of execution of sentences and detention requires knowledge of the peculiarities of culture and practical skills in intercultural communication;

2) interpenetration of cultures; expansion of linguistic and cultural knowledge, skills related to adequate use of language means and rules of speech and non-speech behavior in accordance with the norms adopted in the country of the language being studied;

\footnotetext{
${ }^{*}$ Corresponding author: ninashilina87@mail.ru
} 
3) need to increase the level of culture of specialists in working with information (including foreign language), with people of different social groups and cultures.

In order to form foreign-language sociocultural competence of cadets, it is necessary a special form of organization of educational activities, which contributes to activities of cadets during the lessons, to the formation and the development of professional skills of cadets, to the formation of communication skills. One of the effective means of ensuring a high level of training of specialists is the use of interactive learning technologies, which bring students as close as possible to the real situation of communication and develop such qualities as independence, responsibility for decision-making, stimulate cognitive and creative activity of cadets.

In connection with the above mentioned, the problem of formation of foreign-language sociocultural competence of cadets of educational organizations of the Federal Penal Service of the Russian Federation in conditions of application of interactive technologies becomes particularly urgent.

The formation of sociocultural competence in professional terms among students of non-linguistic universities was reflected in the works of M.R. Vanyagina [1], L.P. Kostikova [2], V.V. Safonova [3], etc. Didactic bases of use forms of interactive learning technologies in the educational process were developed by A.A. Verbitsky [4], A.M; Smolkin [5], etc.

The purpose of the study is to identify pedagogical conditions for the formation of foreign-language sociocultural competence of cadets of educational organizations of the Federal Penal Service of the Russian Federation.

The object of the study is the formation of foreign-language sociocultural competence of cadets.

The subject of the study is pedagogical conditions of the formation of foreign-language sociocultural competence of cadets.

The following methods were used during the study: theoretical (analysis; synthesis; concretization; generalization); diagnostic (questionnaire; testing) empirical (study of experience of educational organizations, normative and educational-methodological documentation); experimental (stating, forming, control experiments).

Foreign-language sociocultural competence of cadets is an integrative personal education, characterized by the ability to establish links between knowledge and situation, the ability to detect the problem, to find a way to solve it, the formation of personal entities in cadets that promote sociocultural adaptation (tolerance to representatives of foreignlanguage culture, empathetic abilities of the participant of intercultural communication).

The structure of foreign-language sociocultural competence of cadets is revealed through interaction of the following components: cognitive (knowledge of equivalence/nonequivalence relations between the units of foreign and native language; of peculiarities of verbal and non-verbal behavior in spheres of communication, of universal and culturespecific studied countries and peoples, general and specific in their worldview); activity (ability to navigate in sociocultural markers of authentic language environment and sociocultural characteristics of people, to predict possible sociocultural obstacles in intercultural communication and use ways to eliminate or mitigate them, to adapt to the foreign language environment, following the lines of courtesy, respecting the traditions and lifestyle of people of a different cultural community; skills to identify and distribute culturally marked words and phrases, cultural information in oral and written texts); personal (qualities of the person, including cultural, sociolinguistic observation, sociocultural susceptibility, sociocultural impartiality, ability to sociocultural education, tolerance to representatives of foreign language culture, empathic abilities of the participant of intercultural communication). 
Effective formation of foreign-language sociocultural competence of cadets is achieved by realization of a set of pedagogical conditions, the basis of which is taking into account the specifics of the educational environment of the university, inclusion in the educational process of classes containing interactive learning technologies, creation of a didactic interactive environment taking into account the structure, the set of components of foreignlanguage sociocultural competence.

Experimental work was carried out under the conditions of the educational process by the method of stating, forming and control stages of the pedagogical experiment, testing, questionnaire, analysis of the results of the training activities of cadets, analysis of the products of the activities of cadets, performance of creative tasks and exercises, method of mathematical statistical processing of data.

The following methods were used to determine the levels of the formation of foreignlanguage sociocultural competence of cadets: language-science testing; reading, translation, analysis of authentic texts; questionnaire for diagnosis of an empathy formation, questionnaire for determination of the level of foreign language training.

According to the results of the diagnostics carried out at the stating stage of the experiment, it was revealed that the foreign-language sociocultural competence of cadets was not sufficiently formed. Thus, according to the cognitive criterion: $27 \%$ of cadets showed a high level of formation of lexical-grammatical knowledge, $40 \%$ - the average level, $33 \%$ - the low level; according to the activity criterion: Most cadets (40\%) have an average level of formation of skills of reading authentic texts and transmitting their content in a foreign language, $24 \%$ of students - a high level, $36 \%$ - a low level; according to the personal criterion: $28.0 \%$ of respondents have a low level, $53.0 \%$ are average, and $19.0 \%$ are high. Figure 1 shows the results of the reporting stage of the experiment.

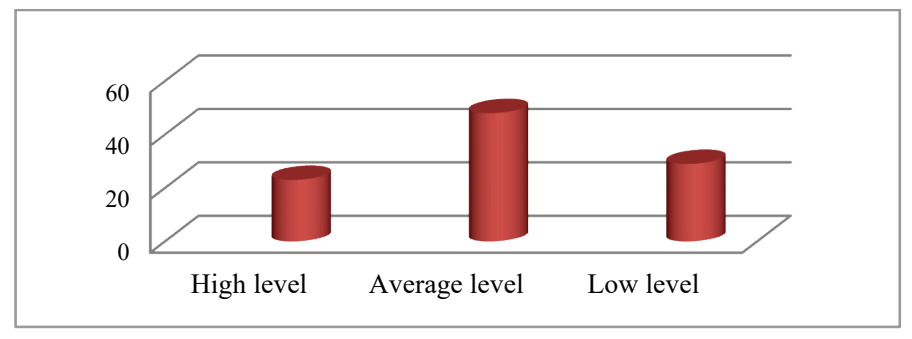

Fig.1 Level of the formation of foreign-language sociocultural competence (stating stage of experiment)

The stating stage of the experiment showed that the majority of respondents are at the average and low level of the formation of foreign-language sociocultural competence.

The second stage of the experiment - forming - was aimed at the formation of foreignlanguage sociocultural competence taking into account the pedagogical conditions that we have identified.

\section{Specifics of the educational environment of the non-linguistic university}

A feature of teaching foreign language communication in non-language universities is professionally-oriented training, which provides for the formation of the ability of students to communicate in specific professional, business, scientific spheres and situations taking into account the peculiarities of professional thinking. According to the Concept for the Development of the Penal System until 2020, one of its directions is the development of 
international cooperation with the penal systems of foreign states, international bodies and non-governmental organizations. Thus, not only knowledge of a foreign language is necessary, but also familiarity with the culture, traditions and art of speakers of a foreign language. This condition provides for targeted work in educational organizations of the Federal Penal Service of the Russian Federation. Implementation of this condition provides for the use of interactive learning technologies, which allow cadets in the training and playing field to play various job and personal roles and master them.

\section{Use of interactive learning technologies in the educational process}

Compliance with this condition was directed to:

- to the development of the cognitive component. The topics of classes were in accordance with the program of a certain specialty or direction of training: "Psychology as science," Legal psychology, "Personality," Law. Branches of Law, "Law Enforcement," etc. In the formation of the cognitive component, it is appropriate to use group interactive learning technologies in classes, namely discussion technologies (discussions, situation analysis, case method, Brainstorming, debate, etc.).

- to the development of the activity component. It is recommended to use both group (game) and individual interactive learning technologies (performance of practical tasks and training).

- to the development of personal component of foreign-language socio-cultural competence of cadets. It is necessary to use discussion (analysis of situations, method of "cases"; discussion), as well as group types of interactive learning technologies (role game, didactic game, etc.).

\section{Creation of didactic interactive conditions taking into account the structure and components of foreign-language sociocultural competence}

Didactic conditions is a specially organized situation aimed at creating a set of didactic conditions that facilitate cadets' acquisition of certain knowledge, skills and skills in a particular discipline, in which the goals, content, methods and organizational forms of learning become mobile and accessible for change.

During the implementation of this condition, the classes were aimed at informing about the peculiarities of verbal and non-verbal behavior in the studied spheres of communication, about universal and culture-specific countries and peoples, general and specific in their worldview (Cognitive component), development of skills to navigate sociocultural markers of authentic language environment and sociocultural characteristics of people, to predict possible sociocultural interference in conditions of intercultural communication and to use ways of their elimination or mitigation, to adapt to foreignlanguage environment, (Activity component), development of personality qualities, including cultural, sociolinguistic observation, sociocultural susceptibility, sociocultural impartiality, ability to sociocultural education; tolerance to representatives of foreign language culture, empathic abilities of the participant of intercultural communication (personality component).

Repeated diagnosis showed positive dynamics of formation levels of foreign-language sociocultural competence of cadets (Figure 2). At the end of the forming experiment, there was a shift in the number of cadets with high (63\%) and average (37\%) levels of formation of foreign-language sociocultural competence. 


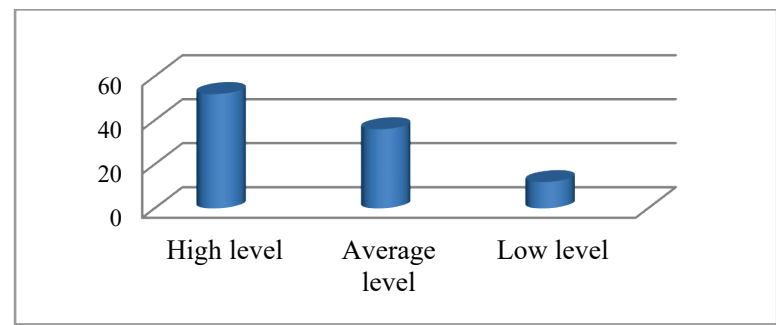

Fig.2 Level of formation of foreign-language sociocultural competence (control stage of the experiment)

The efficiency of formation of foreign-language sociocultural competence of cadets of educational organizations of the Federal Penal Service of the Russian Federation provides a set of theoretically justified and experimentally confirmed pedagogical conditions: taking into account the specifics of the educational environment of the university; inclusion in the educational process of interactive technologies of education, creation of a didactic situation taking into account the structure, set of components of foreign-language sociocultural competence.

\section{References}

1. M.R. Vanyagina, Formation of socio-cultural competence among cadets of military universities in the process of learning English language (2010)

2. L.P. Kostikova, Formation of linguistic and cultural competence of students based on acmeological approach (2014)

3. V.V. Safonova, Sociocultural Approach to Teaching Foreign Language as a Specialty (1992)

4. A.A. Verbitsky, Teaching Methods and Pedagogical Technologies (2018)

5. A.M. Smolkin, Methods of active training (1991) 